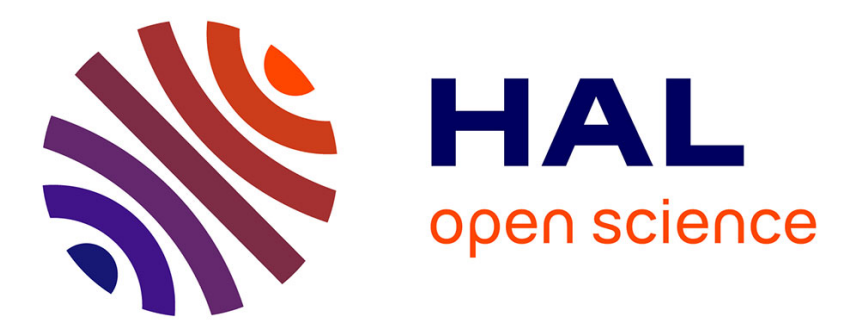

\title{
Modeling field of view effect on the ground observations of directional brightness temperature over a maize canopy
}

Xingfa Gu, Jean-François Hanocq, Tao Yu, Guoliang Tian, Michel Legrand, Roland Bosseno

\section{To cite this version:}

Xingfa Gu, Jean-François Hanocq, Tao Yu, Guoliang Tian, Michel Legrand, et al.. Modeling field of view effect on the ground observations of directional brightness temperature over a maize canopy. IEEE international geoscience and remote sensing symposium, Jul 2003, Toulouse, France. 10.1109/IGARSS.2003.1295539 . hal-02760257

\section{HAL Id: hal-02760257 \\ https://hal.inrae.fr/hal-02760257}

Submitted on 12 Aug 2021

HAL is a multi-disciplinary open access archive for the deposit and dissemination of scientific research documents, whether they are published or not. The documents may come from teaching and research institutions in France or abroad, or from public or private research centers.
L'archive ouverte pluridisciplinaire HAL, est destinée au dépôt et à la diffusion de documents scientifiques de niveau recherche, publiés ou non, émanant des établissements d'enseignement et de recherche français ou étrangers, des laboratoires publics ou privés.

\section{(c)(1)}

Distributed under a Creative Commons Attribution| 4.0 International License 


\section{Modeling field of view effect on the ground observations of directional brightness temperature over a maize canopy}

\author{
Xingfa GU, Jean-Francois HANOCQ \\ CSE-INRA, \\ Avignon, France \\ e-mail: gu@avignon.inra.fr
}

\author{
Michel LEGRAND \\ Université des Sciences et Technologies de Lille \\ e-mail: legrand@loa.univ-lille1.fr
}

\author{
Tao YU, Guoliang TIAN \\ LARSIS-IRSA-CAS, Beijing, China \\ e-mail: yutao@irsa.irsa.ac.cn \\ Roland BOSSENO \\ IRD / CSE-INRA, Avignon, France \\ e-mail: rbosseno@avignon.inra.fr
}

\begin{abstract}
Composite scene of row crops induced an unavoidable error in ground measurements of directional brightness temperature (DBT) due to the use of wide field of view (FOV). The measurement results vary with sample size and position, detector height and view direction, and bias due to project principle. This is called FOV effect. The study focuses on the estimation of FOV effect on the measurements of maize canopy using a computational geometric $2 \mathrm{D}$ model. The model was developed to simulate the fractional variations of canopy brightness temperature components. The simulation results revealed that the errors caused by FOV effect have a complex feature. Generally, vegetation fraction is always over counted in the nadir view, errors increase dramatically with the decrease of detector height as well as the enlargement of sample size, the deviation of the error corresponding to detect position is small; in oblique view, the errors are limited to a low level due to an effect called compensation effect. However, the deviation of the error keeps large when the sample size is small. Nevertheless, the best approach to reduce FOV effect in ground observation is levering the detector to a higher altitude as the model suggested.
\end{abstract}

Keywords- ground observation; row crops; FOV effects; directional brightness temperature

\section{INTRODUCTION}

Experimental study in real condition is considered as the ultimate approach to clearly define DBT variations. Recently, many techniques have been applied in ground measurements, such as tripod, goniometer system etc. [1, 2]. However, these devices were designed fitfully for the measurements over homogeneous canopy, when the targets are row crops, such as cotton, maize, and sunflower, problems are evoked in the observations due to 3 dimension structure of the canopies.

Theoretically, the radiation received by a detector in a particular direction is emitted by an elemental surface whose size is greatly smaller comparing with the distance between the target and the detector to restrict the variance of directional angle within a narrow range which leads to a small FOV and solid angle. On the other hand, the target size should be large enough to represents the target spatial feature well. Ideally, when the detector is far away from the targets (e.g. space borne), FOV of the sample turns to zero, the measured value keeps constant in spite of the changes of sample shape, size and position. In actual measurement, Walthall et al. advised a FOV of $2^{\circ}$ to $3^{\circ}$ to accurately obtain target spectral directional features[3]. However, in ground level experiments, large FOV has been widely used for different purposes (e.g. to filter the heterogeneity of the target surface, to ease the data processing) in the actual measurements over row crops. Unavoidably, these measurements will induce an error in the observations due to the angular variations and position dependence of targets DBT. Various FOV have been used in field experiments. Lagouarde et al. took advantage of two $35^{\circ} \mathrm{FOV}$ radiometers mounted at the end of two 2 meter arms of a tripod to measure DBT of a maize canopy[2]. As he mentioned, the response of the radiometers results from the contribution of several angles which smooth the angular variations significantly.

Until now, few methods have been provided to analyse the bias caused by FOV effect in ground level measurement. The objective of this study is to propose a geometrical model to evaluate the errors caused by FOV effect in ground measurement. The model allows the calculation of vegetation, sunlit and shaded soil fractions which are used as index to analyse the error caused by the changes of canopy geometrical structure, sample size and position and measuring geometry.

\section{A GEOMETRICAL MODEL FOR FOV EFFECT INVESTIGATION}

\section{A. Maize canopy geometrical structure and three fraction assumption}

Row crop geometry described by Jackson et al.[4] was adopted that the plant hedgerows are abstracted as extended

This study is supported by INRA France and China's Funds (Grant No. 2000077902, 2002AA130010-2, and CX020011) 
rectangular solids without gaps, its bottom touches soil plane which is an ideal flat surface.

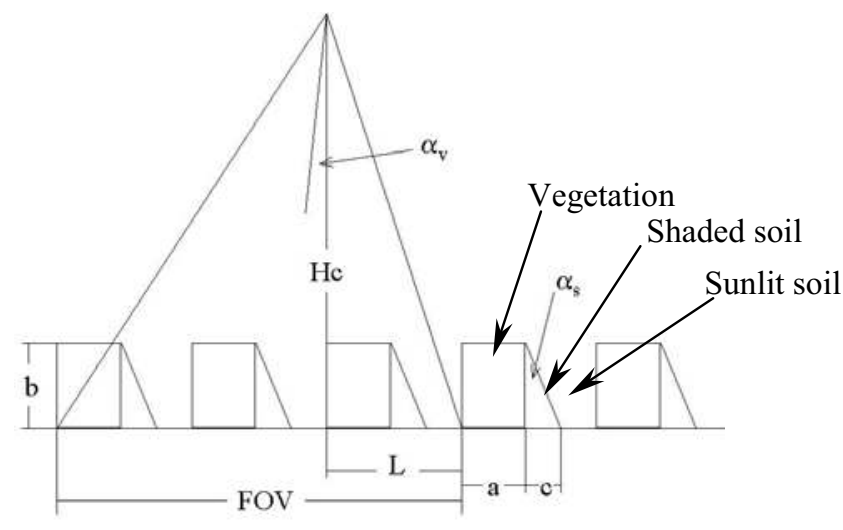

Figure 1. Abstraction of row crop model and geometry of the measurement

Figure 1 shows the definition of variables as seen in the plane cross the row. Hc is the altitude of detector, $\mathrm{b}$ and a are the height and width of rectangles; L is the row spacing; the sun and view direction projected in perpendicular plane of the rows are defined by $\alpha_{S}$ and $\alpha_{V}$ respectively. Since the asymmetry feature of the canopy, $\alpha_{S}$ is limited within $0^{\circ}$ and $90^{\circ}$, while $\alpha_{V}$ is from $-90^{\circ}$ to $90^{\circ}$. When $\alpha_{V}>0$, the view is in the same side of the sun, when $\alpha_{V<0}$, the view is in the opposite side of the sun. The inclination angle $\alpha$ is calculated as $\tan \alpha=\tan \gamma \sin \varphi$, where $\gamma$ and $\varphi$ are the zenith and azimuth angle defining the sun or view direction. The length of vegetation shadow on the soil plane is c, it equals to $b \tan \alpha_{S}$. In this figure, FOV covers 3 row spacing $(3 \mathrm{~L})$, the corresponding angle is $\theta \mathrm{v}$. For the condition that $\alpha_{V}$ is not zero, $\theta \mathrm{v}$ is:

$\theta_{v}=\operatorname{atg}\left(\frac{-\frac{H c\left(1+\operatorname{tg}^{2} \alpha_{v}\right)}{k L}+\sqrt{\left(\frac{H c\left(1+\operatorname{tg}^{2} \alpha_{v}\right)}{k L}\right)+\operatorname{tg}^{2} \alpha_{v}}}{\operatorname{tg}^{2} \alpha_{v}}\right)$

where, $k$ is the number of row within the view. If $\alpha_{V}$ is zero (view the nadir), we get:

$$
\theta_{v}=2 \operatorname{atg}\left(\frac{k L}{2 H c}\right)
$$

\section{B. Calculation of each component fraction}

With the simplification of this 2D model, component fractions in the scene of detector view could be calculated by their projection areas on the soil plane, which equal to the length ratio of components to the sample side in the cross row plane.

\section{ANALYSIS OF MODEL SIMULATION}

\section{A. Analyzing FOV effect in the nadir view}

Figure 2 shows the fraction errors caused by detect position for nadir view when camera moves within a distance of one row spacing. In the figure, $\mathrm{Cv}, \mathrm{Cse}, \mathrm{Cso}$ are actual fractions of vegetation, sunlit and shaded soil; $C$ vidl, Cseidl Csoidl are that for ideal condition correspondingly. The parameter values of canopy geometry and sun-view geometry as input are shown in Table 1, where, the length of row spacing $L$ is assigned as the unit with a value of 1 , other geometrical parameters are shown as the ratio with $L$. For example, camera's height $H c$ is $10 L$, so the value of $H c$ is 10 in the table. The simulation interval is $1 / 100$ of $L$.

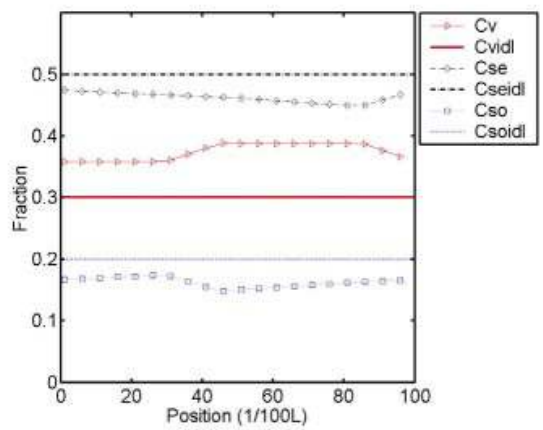

Figure2. The fractions error varies with detect position for the nadir view

TABLE1. CANOPY GEOMETRY AND SUN-VIEW GEOMETRY FOR THE SIMULATION

\begin{tabular}{|c|c|c|c|c|c|c|c|}
\hline$H c$ & $K$ & $a$ & $B$ & $c$ & Cvidl & Cseidl & Csoidl \\
\hline 10 & 5 & 0.3 & 0.6 & 0.2 & 0.3 & 0.5 & 0.2 \\
\hline
\end{tabular}

The value of component fraction fluctuates with the move of detector. Compared with ideal condition, vegetation is always over counted, soil part is less estimated. This bias comes from the projective geometrical principal, which appears in every sub view. If target height is comparable with camera's altitude, more bottom part of the field is obscured by upper part. In this simulation, the vegetation fraction is over counted up to 0.1 which is $1 / 3$ of ideal vegetation fraction. With the move of the camera, the fluctuation of $C v$ has a range of 0.03 . This will let the actual measurement have many values due to the random selection of detect position. In this research, we appoint the difference between simulated and ideal vegetation fraction $\Delta C_{v}$ and fluctuation range $\delta C_{v}$ as the index to indicate the error cause by FOV effect: 
(4)

$$
\delta C_{v}=C_{v \max }-C_{v \min }
$$

where $C_{v \text { mean }}, C_{v \max }$ and $C_{v \min }$ are the mean, maximum and the minimum value of simulated $C_{v}$. The error of vegetation fraction caused by FOV effect in this example is 0.08 , the vegetation fraction fluctuation is 0.03 .

\section{B. View zenith's influence and compensation effects for oblique view}

Figure 3 and 4 display the oblique view with $15^{\circ}$ inclination at two directions along the sun and opposite to the sun respectively. Canopy geometry and sun-view geometry for the simulation are shown in Table 2.

TABLE 2. CANOPY GEOMETRY AND SUN-VIEW GEOMETRY FOR THE SIMULATION

\begin{tabular}{ccccccccc}
\hline$\alpha_{V}$ & $H c$ & $K$ & $a$ & $B$ & $C$ & Cvidl & Cseidl & Csoidl \\
\hline $15^{\circ}$ & 10 & 5 & 0.3 & 0.6 & 0.2 & 0.46 & 0.5 & 0.04 \\
\hline$-15^{\circ}$ & 10 & 5 & 0.3 & 0.6 & 0.2 & 0.46 & 0.34 & 0.2 \\
\hline
\end{tabular}

Compared with the nadir view, curves of off nadir view show a new feature that the values of component fractions fluctuate around the ideal lines corresponding to camera position. The variations of vegetation fraction $\Delta C_{v}$ and $\delta C_{v}$ are 0.01 and 0.04 respectively. $\Delta C_{v}$ is much smaller than that in the nadir view. We related this to the contribution of compensation effect. In analysis, FOV is divided into two parts from the ideal angle which was assigned to be the zenith of the view: the upper part and the lower part. The view zenith of upper part is larger than the ideal angle, the zenith of lower part is less than the ideal angle. In upper part of view, vegetation fraction is over counted comparing with the ideal view, which leads to a less count of sunlit/shaded soil. On the contrary, vegetation fraction is less counted in the lower part of view, which lead to an over count of sunlit and shaded soil fractions. These two bias compensate with each other, their combined influence reduces the fraction error in the observations.

Comparing Figure 3 and 4, component fractions have different features between the view along the sun and that opposite to the sun. For vegetation component, two views have the same value of vegetation fraction except a displacement of the curves. Because of the asymmetry of field structure, the vegetation fraction is of the same shape when viewing with the same zenith from two opposite directions. The difference is a shift between these two curves due to the start positions for the simulation. On contrary, the view direction has a great influence on the values of sunlit and shaded soil fractions. Viewing along the sun, part of the shaded soil was sheltered by the canopy. With the move of camera, the shaded soil fraction fluctuates in a large range. When view from the opposite direction of the sun, part of sunlit soil was obscured by the canopy instead of shaded soil, which leads to a large shake of sunlit soil fraction, the sun shaded soil fraction, however, has no change within the whole range of the observation.

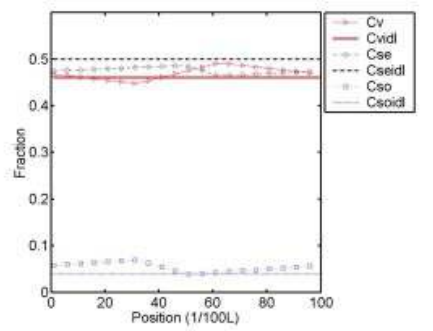

Figure3. Off nadir view with a zenith angle of $15^{\circ}$ along the sun

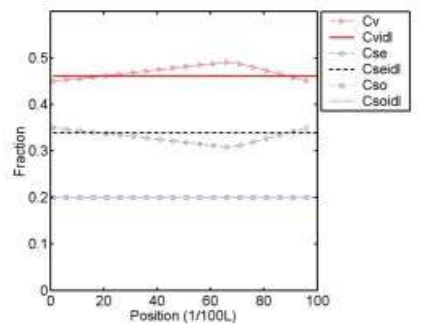

Figure 4. Off nadir view with a zenith angle of $15^{\circ}$ opposite to the sun

\section{CONCLUSION}

In this study, a modified row crop model was used to evaluate measuring geometry influence on the extraction of canopy composite directional brightness temperature. Despite of its simplification, the model demonstrates the systematic errors caused by the definite height of detector and reveals an effect of compensation for the off nadir viewing. With the increase of sample area's size and decrease of detector height, the errors of fraction calculation is enlarged continuously, the canopy fraction is always over estimated, sunlit/shaded soil's fractions are less estimated. In the off nadir view, the errors are limited to a low range due to the compensation effect within field of view for several sample sizes. This angular effect reduce the error for fraction estimation efficiently, which leads to more sophistic sampling design in the practical experiment. Anyway, the best method to reduce the error is et the detector to a higher altitude as mentioned before.

\section{REFERENCES}

[1] R.C. Vining and B.L. Blad, "Estimation of sensible heat flux from remotely sensed canopy temperatures", Journal of Geophysical Research, 97 (D17), 18951-18954, 1992.

[2] J.P. Lagouarde, Y.H. Kerr, and Y. Brunet, "An experimental study of angular effects on surface temperature for various plant canopies and bare soils", Agricultural and forest meteorology, 77, 167-190, 1995.

[3] C. Walthall, J.L. Roujean, and J. Morisette, "Field and landscape BRDF optical wavelength measurements: experience, techniques and the future", Remote sensing review, 18, 503-531, 2000.

[4] R.D. Jackson, R.J. Reginato, P.J.J. Pinter, and S.B. Idso, "Plant canopy information extraction from composite scene reflectance of row crops", Applied Optics, 18, 3775-3782, 1979. 